\title{
COVID-19 Infections Among General Internal Medicine Faculty at a New York Teaching Hospital: a Descriptive Report
}

J Gen Intern Med 36(4):1153-5

DOI: $10.1007 / \mathrm{s} 11606-020-06431-8$

(c) Society of General Internal Medicine 2021

\section{INTRODUCTION}

General Internal Medicine (GIM) faculty at New York-Presbyterian/Weill Cornell Medicine were frontline providers during the COVID-19 pandemic in the disease epicenter of the USA. Within 3 weeks of our hospital's first COVID-19 positive patient, several clinical faculty reported COVID-like illness (CLI) and/or SARS-CoV-2 PCR positivity.

Data on infection risks among US healthcare personnel (HCP) are not well documented. We developed a quality improvement project to (1) estimate the prevalence of COVID-19 among our patient-facing faculty during NYC's first 6 weeks of the pandemic and (2) characterize potential transmission sources to mitigate risks of exposure.

\section{METHODS}

GIM clinical faculty in full-time direct patient contact from March 1 to April 13, 2020, received a one-time email link to an anonymous survey. Data were collected from April 6 to April 20, 2020. Thirty multiple-choice and open-ended questions were designed to capture presumed source of exposure (work vs. community), place of direct patient care (hospital vs. ambulatory), and access to and use of personal protective equipment (PPE). Hospital PPE guidance based on the $\mathrm{CDC}$ varied during the study period (Fig. 1). From March 1 to March 17, PPE included contact and airborne precautions (with eye protection). Guidelines changed on March 18th restricting N95 respirators for aerosol-generating procedure. Following an increase in supply, N95s were again recommended for routine care of patients under investigation (PUI)/COVID-19-positive patients after April 10th. Faculty reporting either CLI or a positive SARS-CoV-2 PCR were categorized as CLI/ COVID-19. Those without CLI or negative PCR test were categorized as COVID-negative. (HCP testing became

Received June 30, 2020

Accepted December 9, 2020

Published online January 27, 2021 available 3 days before the study period ended.) Data were aggregated for descriptive summary statistics as the study was intended for quality improvement and was not powered to detect statistical significance. The IRB determined that the study was exempt from review.

\section{RESULTS}

Among 135 GIM faculty, 114 (84\%) were eligible to receive the survey. Seventy-six were hospital medicine (HM) and 38 were ambulatory internal medicine (AIM) faculty. Overall response rate was $61 \%$ (70/114), 53\% from HM (40/76) and $79 \%$ from AIM clinicians (30/38). All HM faculty worked with either physician assistants or house staff. Resident supervision varied by AIM practice sites.

Twenty-one faculty were CLI/COVID-19 (30\% of respondents) with eight confirmed by SARS-CoV-2 PCR $(8 / 21,38 \%)$ (Table 1$)$. Over a quarter $(6 / 21,29 \%)$ reported symptoms within 7 days of service with $57 \%(12 / 21)$ working in the ambulatory setting. Over half of CLI/ COVID-19 faculty $(13 / 21,62 \%)$ cared for patients with "unknown" COVID status (absence of CLI on encounter).

The peak incidence of CLI/COVID-19 faculty preceded our hospital's highest COVID-19 inpatient census by nearly 14 days (Fig. 1). AIM attendings reported illness earlier than HM attendings. Two faculty were hospitalized $(2 / 21,9.5 \%)$ including one to the intensive care unit $(1 / 21$, $4.8 \%$ ); none required intubation. There were no deaths.

While nearly one-third of exposures were suspected from the community $(6 / 21,28.6 \%)$, only three $(3 / 21$, $14 \%)$ affirmed a community-based source. Among the other 18 CLI/COVID-19 faculty, 39\% (7/18) performed more auscultation during exams than COVID-negative faculty $(6 / 48,13 \%)$. N95 respirators were used less often when seeing patients with CLI (8/18, 44\% use versus $35 /$ 48, 73\% among CLI/COVID-19 and negative faculty, respectively). Twenty percent of respondents disagreed that PPE was always available when needed; most commonly cited as missing were eye protection and sizeappropriate N95s. Only 22\% (4/18) of CLI/COVID-19 faculty reported adherence with social isolation as compared to $60 \%$ (29/48) among those COVID-negative. 


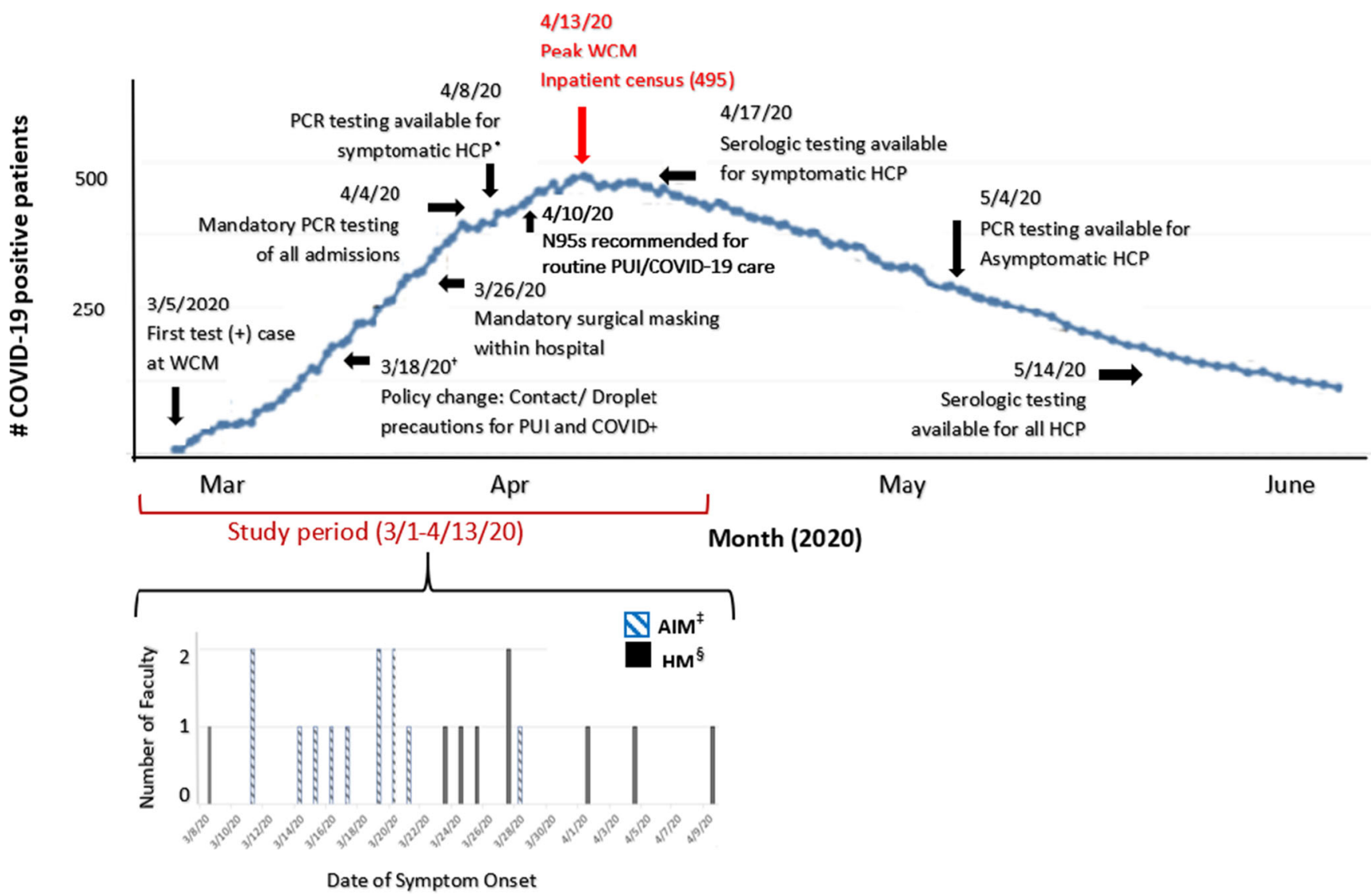

Figure. 1 Timeline of symptom onset for CLI/COVID-19-positive GIM faculty compared to total COVID-19 test positive inpatient census.

${ }^{*} \mathrm{HCP}$, health care personnel. ${ }^{\dagger}$ Before $3 / 18 / 20$, hospital recommendation. ${ }^{*} \mathrm{AIM}$, ambulatory internal medicine. ${ }^{\S} \mathrm{HM}$, hospital medicine.

Table 1 Characteristics of GIM Faculty Surveyed

\begin{tabular}{|c|c|c|c|c|}
\hline & \multicolumn{2}{|c|}{ COVID positive $*, N=21$} & \multicolumn{2}{|l|}{ COVID negative ${ }^{\dagger}, N=49$} \\
\hline & $\begin{array}{l}\mathrm{CLI}^{\ddagger}, N=13 \\
(\%)\end{array}$ & $\begin{array}{l}\text { SARS-CoV-2 PCR }+, N=8 \\
(\%)\end{array}$ & $\begin{array}{l}\text { Asymptomatic, } N=46 \\
(\%)\end{array}$ & $\begin{array}{l}\text { SARS-CoV-2 PCR -, } N=3 \\
(\%)\end{array}$ \\
\hline \multicolumn{5}{|c|}{ Characteristics of GIM faculty surveyed $(\mathrm{N}=70)$} \\
\hline \multicolumn{5}{|c|}{ Specialty } \\
\hline $\begin{array}{l}\text { Ambulatory internal medicine } \\
\text { (AIM) }\end{array}$ & $8(62)$ & $4(50)$ & $16(35)$ & $2(67)$ \\
\hline Hospital medicine $(\mathrm{HM})$ & $5(38)$ & $4(50)$ & $30(65)$ & $1(33)$ \\
\hline \multicolumn{5}{|l|}{ Age } \\
\hline$<40$ & $9(69)$ & $5(63)$ & $26(57)$ & $1(33)$ \\
\hline $40-60$ & $0(0)$ & $2(25)$ & $16(35)$ & 0 \\
\hline$>60$ & $4(31)$ & $1(13)$ & $3(6)$ & $2(67)$ \\
\hline Missing & & & $1(2)$ & \\
\hline \multicolumn{5}{|l|}{ Sex } \\
\hline Female & $8(62)$ & $6(75)$ & $27(59)$ & $2(67)$ \\
\hline \multicolumn{5}{|l|}{ Race } \\
\hline Asian & $8(62)$ & $3(38)$ & $16(35)$ & 0 \\
\hline Black or African American & $0(0)$ & $0(0)$ & $1(2)$ & 0 \\
\hline Hispanic & $0(0)$ & $1(13)$ & $3(6)$ & 0 \\
\hline White & $5(38)$ & $4(50)$ & $23(50)$ & $3(100)$ \\
\hline Other & $0(0)$ & $0(0)$ & $3(6)$ & 0 \\
\hline \multicolumn{5}{|l|}{ Type of patients seen ${ }^{\S}$} \\
\hline Known COVID & $0(0)$ & $2(25)$ & $19(41)$ & $2(67)$ \\
\hline Known non-COVID & $3(23)$ & $1(13)$ & $5(11)$ & 0 \\
\hline Mixed & $1(8)$ & $1(13)$ & $11(24)$ & 0 \\
\hline Unknown status & $9(69)$ & $4(50)$ & $11(24)$ & $1(33)$ \\
\hline \multicolumn{5}{|c|}{ Characteristics of COVID-positive GIM faculty surveyed $(N=21)$} \\
\hline \multicolumn{5}{|c|}{ Total days in patient care prior to onset of symptoms } \\
\hline Less than 7 & $4(31)$ & $2(25)$ & & \\
\hline $8-14$ & $4(31)$ & $3(38)$ & & \\
\hline More than 14 & $5(38)$ & $3(38)$ & & \\
\hline \multicolumn{5}{|l|}{ Symptoms } \\
\hline Fever & $9(69)$ & $7(88)$ & & \\
\hline
\end{tabular}


Table 1. (continued)

\begin{tabular}{|c|c|c|c|c|}
\hline & \multicolumn{2}{|c|}{ COVID positive $*, N=21$} & \multicolumn{2}{|l|}{ COVID negative ${ }^{\dagger}, N=49$} \\
\hline & $\begin{array}{l}\mathrm{CLI}^{\ddagger}, N=13 \\
(\%)\end{array}$ & $\begin{array}{l}\text { SARS-CoV-2 PCR }+, N=8 \\
(\%)\end{array}$ & $\begin{array}{l}\text { Asymptomatic, } N=46 \\
(\%)\end{array}$ & $\begin{array}{l}\text { SARS-CoV-2 PCR - } N=3 \\
(\%)\end{array}$ \\
\hline Chills and/or rigors & $9(69)$ & $6(75)$ & & \\
\hline Headache & $8(62)$ & $6(75)$ & & \\
\hline Fatigue & $12(92)$ & $8(100)$ & & \\
\hline Respiratory & $12(92)$ & $6(75)$ & & \\
\hline Myalgias and/or arthralgias & $8(62)$ & $7(88)$ & & \\
\hline GI & $8(62)$ & $6(75)$ & & \\
\hline Anosmia and/or dysgeusia & $9(69)$ & $4(50)$ & & \\
\hline Rash & $1(8)$ & $0(0)$ & & \\
\hline Other & $0(0)$ & $3(38)$ & & \\
\hline \multicolumn{5}{|l|}{ Level of clinical care received } \\
\hline Did not seek care & $10(77)$ & $1(13)$ & & \\
\hline Ambulatory & $3(23)$ & $4(50)$ & & \\
\hline $\begin{array}{l}\text { Emergency room visit } \\
\text { (discharged) }\end{array}$ & $0(0)$ & $1(13)$ & & \\
\hline Hospitalized: inpatient floor & $0(0)$ & $1(13)$ & & \\
\hline Hospitalized: ICU care & $0(0)$ & $1(13)$ & & \\
\hline \multicolumn{5}{|c|}{ Self-reported source of exposure } \\
\hline Community & $4(31)$ & $2(25)$ & & \\
\hline Extremely confident & $2 / 4(15)$ & $1 / 2(13)$ & & \\
\hline Suspected & $2 / 4(15)$ & $1 / 2(13)$ & & \\
\hline Colleague at the workplace & $3(23)$ & $2(25)$ & & \\
\hline Patient in your care & $6(46)$ & $4(50)$ & & \\
\hline Emergency room & $0(0)$ & $1 / 4(13)$ & & \\
\hline Inpatient & $4 / 6(31)$ & $2 / 4(25)$ & & \\
\hline Office & $2 / 6(15)$ & $1 / 4(13)$ & & \\
\hline
\end{tabular}

*COVID-positive $=$ COVID-like illness and/or known SARS-CoV-2 PCR-positive

†COVID negative = asymptomatic and/or known SARS-CoV-2 PCR-negative

tCLI COVID-like illness

\$Status was triaged based on the presence of classic symptoms and/or SARS-CoV-2 PCR results. Patients were of "unknown status" if they did not meet either criteria. Of note, mandatory testing of all admitted patients began on April 4, 2020

\section{DISCUSSION}

Early characterization of potential sources of SARS-CoV-2 virus exposure was critical to improving the safety of our frontline providers. ${ }^{1,2}$ Exposure to PUIs and colleagues with unknown COVID-19 status due to asymptomatic transmission, delayed testing availability, and PPE shortages coupled with delayed national recommendations for universal (hospital and community) masking may have contributed to a third of respondents falling ill. ${ }^{3}$

We acknowledge that the small numbers of surveyed faculty and confirmed COVID-19 status are limitations to the study, but feel there was no negative impact on our intended outcome of identifying and improving prevention practices during a time of limited guidance and availability to testing. Ongoing adherence to public masking and utilization of rapid testing remain critical. ${ }^{4}$ Governments, public health authorities, and hospitals must prioritize the provision of resources and information required to keep the frontline, and the community, safe.

Jennifer I. Lee, $M D^{1,2}$

Brooke W. Bullington, $B A^{3}$

Matthew S. Simon, MD MSc ${ }^{1,2}$

Daniel J. Crossman, $M D^{1,2}$

Arthur T. Evans, MD MPH ${ }^{1,2}$

Margaret L. McNairy, MD MSc ${ }^{1,2,3}$

${ }^{1}$ NewYork-Presbyterian/Weill Cornell Medicine, New York, NY, USA
${ }^{2}$ Department of Medicine, Section of Hospital Medicine, Weill Cornell Medicine, New York, NY, USA

${ }^{3}$ Center for Global Health Weill Cornell Medicine, New York, NY, USA

Corresponding Author: Jennifer I. Lee, MD; Department of Medicine, Section of Hospital Medicine, Weill Cornell Medicine, New York, NY, USA (e-mail: jel9026@med.cornell.edu).

Compliance with Ethical Standards: All ICMJE forms for each author were submitted withe the manuscript. There are no conflicts of interest for any of our authors.

\section{REFERENCES}

1. Ofner-Agostini M, Gravel D, McDonald LC, et al. Cluster of cases of severe acute respiratory syndrome among Toronto healthcare workers after implementation of infection control precautions: a case series. Infect Control Hosp Epidemiol 2006. 27(5):473-478

2. Steensels D, Oris E, Coninx L, et al. Hospital-Wide SARS-CoV-2 Antibody Screening in 3056 Staff in a Tertiary Center in Belgium. JAMA. Published online June 15, 2020. doi:https://doi.org/10.1001/jama.2020.11160

3. Böhmer MM, Buchholz U, Corman VM, et al. Investigation of a COVID-19 Outbreak in Germany Resulting from a Single Travel-Associated Primary Case: a Case Series. Lancet Infect Dis. Published online May 15, 2020. https://doi.org/10.1016/S1473-3099(20)30314-5

4. Thompson S, Eilperin J, Dennis B (2020, May 17). As coronavirus testing expands, a new problem arises: Not enough people to test. The Washington Post. Retrieved from https://www.washingtonpost.com. Accessed 8 Jun 2020

Publisher's Note: Springer Nature remains neutral with regard to jurisdictional claims in published maps and institutional affiliations. 